\title{
Evolution of Lysine Biosynthesis in the Phylum Deinococcus-Thermus
}

\author{
Hiromi Nishida ${ }^{1}$ and Makoto Nishiyama ${ }^{2}$ \\ ${ }^{1}$ Agricultural Bioinformatics Research Unit, Graduate School of Agricultural and Life Sciences, University of Tokyo, Bunkyo-ku, \\ Tokyo 113-8657, Japan \\ ${ }^{2}$ Biotechnology Research Center, University of Tokyo, Bunkyo-ku, Tokyo 113-8657, Japan
}

Correspondence should be addressed to Hiromi Nishida, hnishida@iu.a.u-tokyo.ac.jp

Received 28 January 2012; Accepted 17 February 2012

Academic Editor: Kenro Oshima

Copyright ( $) 2012$ H. Nishida and M. Nishiyama. This is an open access article distributed under the Creative Commons Attribution License, which permits unrestricted use, distribution, and reproduction in any medium, provided the original work is properly cited.

Thermus thermophilus biosynthesizes lysine through the $\alpha$-aminoadipate (AAA) pathway: this observation was the first discovery of lysine biosynthesis through the AAA pathway in archaea and bacteria. Genes homologous to the T. thermophilus lysine biosynthetic genes are widely distributed in bacteria of the Deinococcus-Thermus phylum. Our phylogenetic analyses strongly suggest that a common ancestor of the Deinococcus-Thermus phylum had the ancestral genes for bacterial lysine biosynthesis through the AAA pathway. In addition, our findings suggest that the ancestor lacked genes for lysine biosynthesis through the diaminopimelate (DAP) pathway. Interestingly, Deinococcus proteolyticus does not have the genes for lysine biosynthesis through the AAA pathway but does have the genes for lysine biosynthesis through the DAP pathway. Phylogenetic analyses of $D$. proteolyticus lysine biosynthetic genes showed that the key gene cluster for the DAP pathway was transferred horizontally from a phylogenetically distant organism.

\section{Introduction}

The Deinococcus-Thermus phylum constitutes one of the major bacterial evolutionary lineages $[1,2]$. At present, the genome sequence data of 6 genera (13 organisms) belonging to this phylum are available in the Kyoto Encyclopedia of Genes and Genomes (KEGG) database [3].

Two pathways for lysine biosynthesis have been described, namely, the $\alpha$-aminoadipate (AAA) pathway and the diaminopimelate (DAP) pathway [5]. The AAA pathway has two different types [6]. In T. thermophilus, a gene cluster was found for lysine biosynthesis not through the DAP pathway but through the AAA pathway [6-8]. Although Deinococcus radiodurans has genes homologous to the $T$. thermophilus lysine biosynthetic genes, these genes are scattered on the genome [9]. In addition, the D. radiodurans aspartate kinase that catalyzes the phosphorylation of L-aspartate (the first reaction in the DAP pathway) is structurally and phylogenetically very different from that of T. thermophilus [10]. Recent studies have shown that the genome signatures of these 2 bacteria are different [4], supporting the theory that Deinococcus species acquired genes from various other bacteria to survive different kinds of environmental stresses, whereas Thermus species have acquired genes from thermophilic bacteria to adapt to high-temperature environments [11].

The distribution of lysine biosynthetic genes in the Deinococcus-Thermus phylum has not been clearly described. In this study, we compared the distribution of the genes for lysine biosynthesis between 13 organisms (D. deserti, D. geothermalis, D. maricopensis, D. proteolyticus, D. radiodurans, Marinithermus hydrothermalis, Meiothermus ruber, M. silvanus, Oceanithermus profundus, T. scotoductus, $T$. thermophilus HB8, T. thermophilus HB27, and Truepera radiovictrix).

\section{Methods}

We analyzed the distribution of each of the following 10 enzymes related to lysine biosynthesis through the AAA pathway in the Deinococcus-Thermus phylum: $\alpha$ aminoadipate aminotransferase, homoisocitrate dehydrogenase, LysW- $\gamma$-L-lysine aminotransferase, LysW- $\gamma$-L-lysine 


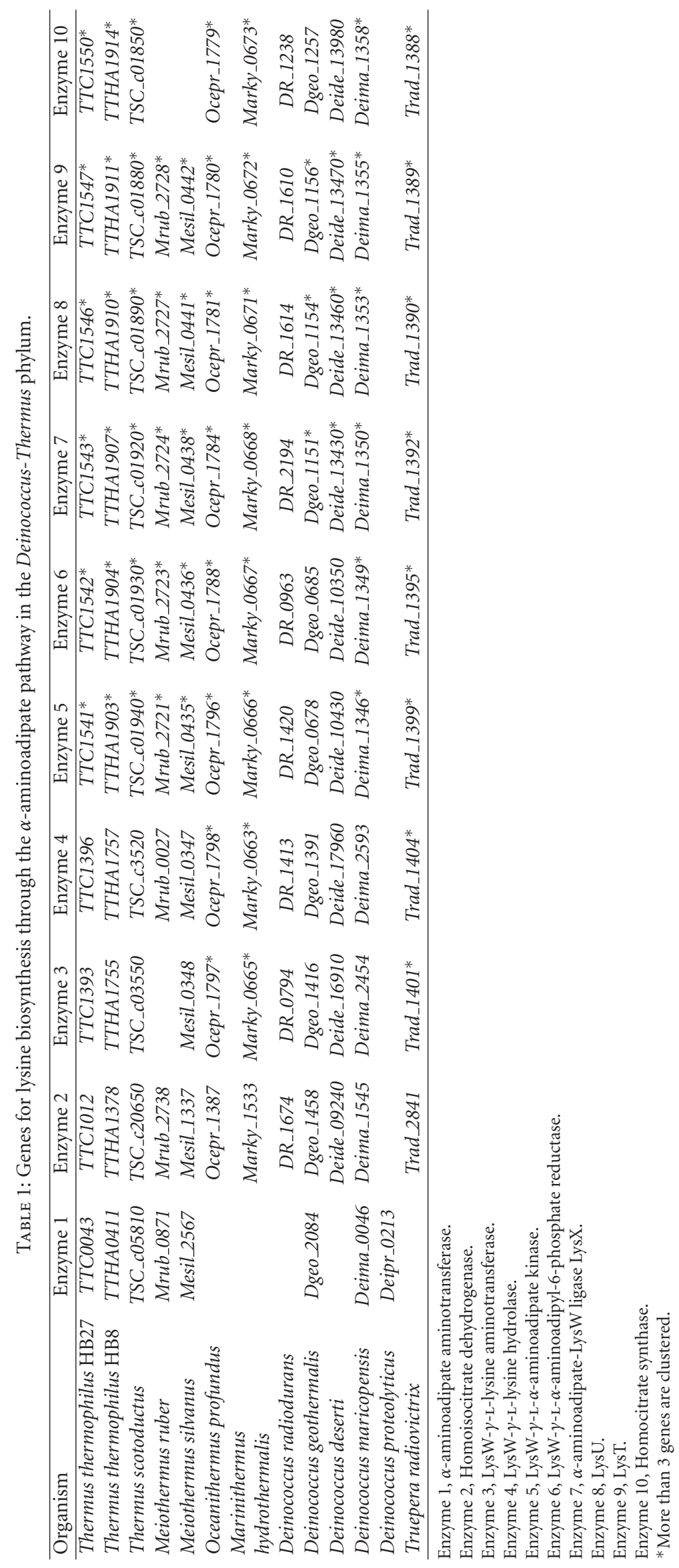


TABle 2: Genes for lysine biosynthesis through the diaminopimelate pathway in the Deinococcus-Thermus phylum.

\begin{tabular}{|c|c|c|c|c|c|c|}
\hline Organism & $\begin{array}{l}\text { Aspartate } \\
\text { kinase }\end{array}$ & $\begin{array}{c}\text { Aspartate- } \\
\text { semialdehyde } \\
\text { dehydrogenase }\end{array}$ & $\begin{array}{l}\text { Dihydrodipicolinate } \\
\text { synthase }\end{array}$ & $\begin{array}{l}\text { Dihydrodipicolinate } \\
\text { reductase }\end{array}$ & $\begin{array}{l}\text { LL- } \\
\text { diaminopimelate } \\
\text { aminotransferase }\end{array}$ & $\begin{array}{c}\text { Diaminopimelate } \\
\text { decarboxylase }\end{array}$ \\
\hline Thermus thermophilus HB27 & ТTC0166 & TTC0177 & TTC0591 & & & \\
\hline Thermus thermophilus HB8 & TTHA0534 & ТTHА0545 & ТTHА0957 & & & \\
\hline Thermus scotoductus & TSC_c07050 & TSC_c08140 & TSC_c10420 & & & TSC_c10870 \\
\hline Meiothermus ruber & Mrub_0976 & Mrub_1641 & Mrub_1335 & & & Mrub_0798 \\
\hline Meiothermus silvanus & Mesil_1711 & Mesil_2173 & Mesil_2308 & & & Mesil_0318 \\
\hline Oceanithermus profundus & Ocepr_1316 & Ocepr_1018 & & & & Ocepr_2076 \\
\hline $\begin{array}{l}\text { Marinithermus } \\
\text { hydrothermalis }\end{array}$ & Marky_1492 & Marky_1381 & Marky_1261 & & & \\
\hline Deinococcus radiodurans & DR_1365 & DR_2008 & & & & $D R \_1758$ \\
\hline Deinococcus geothermalis & Dgeo_1127 & Dgeo_1782 & & & & Dgeo_0790 \\
\hline Deinococcus deserti & Deide_11430 & Deide_15740 & $\begin{array}{l}\text { Deide_1p00310, } \\
\text { Deide_3p00120, } \\
\text { Deide_3p01100 }\end{array}$ & & & $\begin{array}{l}\text { Deide_12830, } \\
\text { Deide_21880 }\end{array}$ \\
\hline Deinococcus maricopensis & Deima_1822 & Deima_2680 & & & & Deima_2660 \\
\hline Deinococcus proteolyticus & Deipr_0941 & Deipr_0985 & Deipr_1377* & Deipr_1378* & Deipr_1376* & $\begin{array}{l}\text { Deipr_0627, } \\
\text { Deipr_1375* }\end{array}$ \\
\hline Truepera radiovictrix & Trad_0977 & Trad_0289 & Trad_1893 & & & Trad_0134 \\
\hline
\end{tabular}

${ }^{*}$ More than 3 genes are clustered.

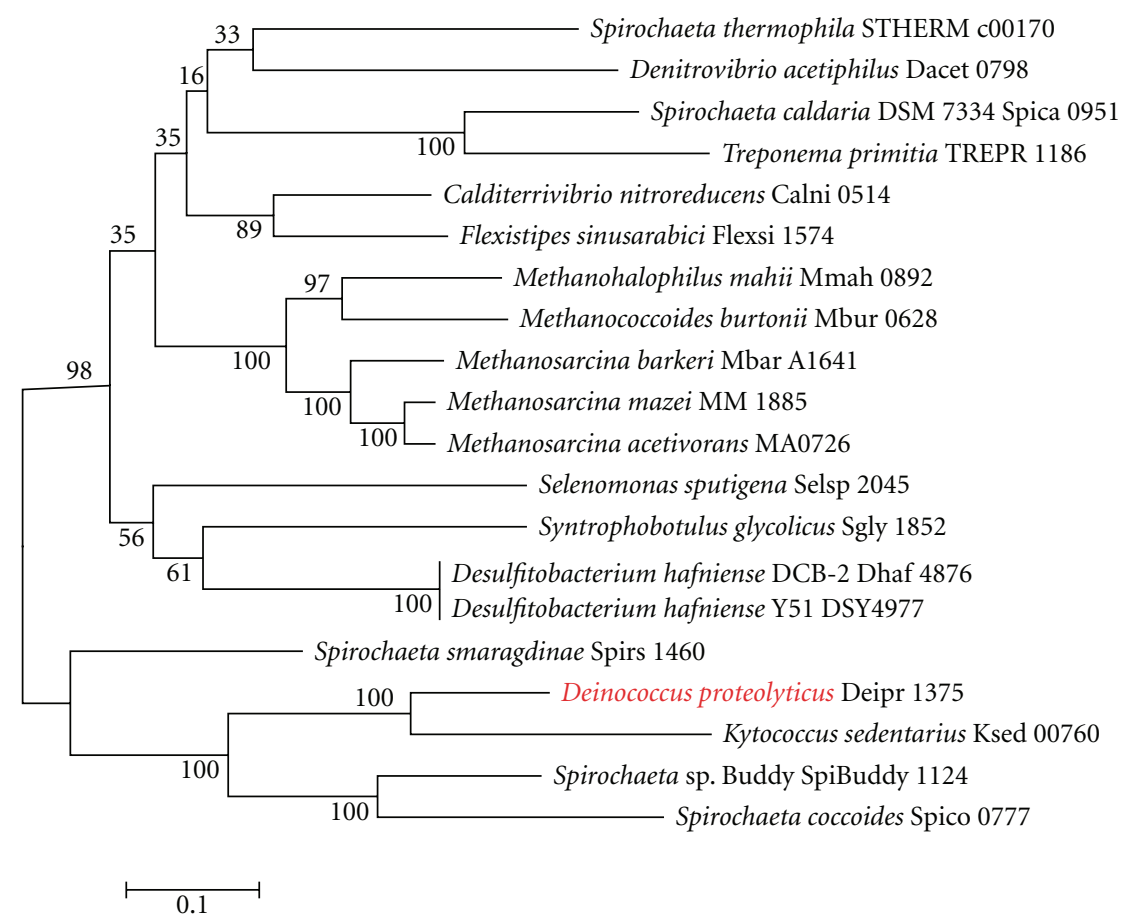

FIGURE 1: Phylogenetic relationship between Deinococcus proteolyticus diaminopimelate decarboxylase and related proteins. Multiple alignment was obtained using the top 20 amino acid sequences of the BLASTp search result for D. proteolyticus diaminopimelate decarboxylase (Deipro 1375), as based on the Kyoto Encyclopedia of Genes and Genomes (KEGG) database. The maximum-likelihood tree was constructed using MEGA software version 5 [12]. The WAG model was used as the amino acid substitution model. The nearest neighbor interchange was used for the maximum-likelihood heuristic method. The $\gamma$-distributed rate was considered, and the number of discrete $\gamma$ categories was 3. Bootstrap analysis was performed with 100 replicates. Red indicates D. proteolyticus. 


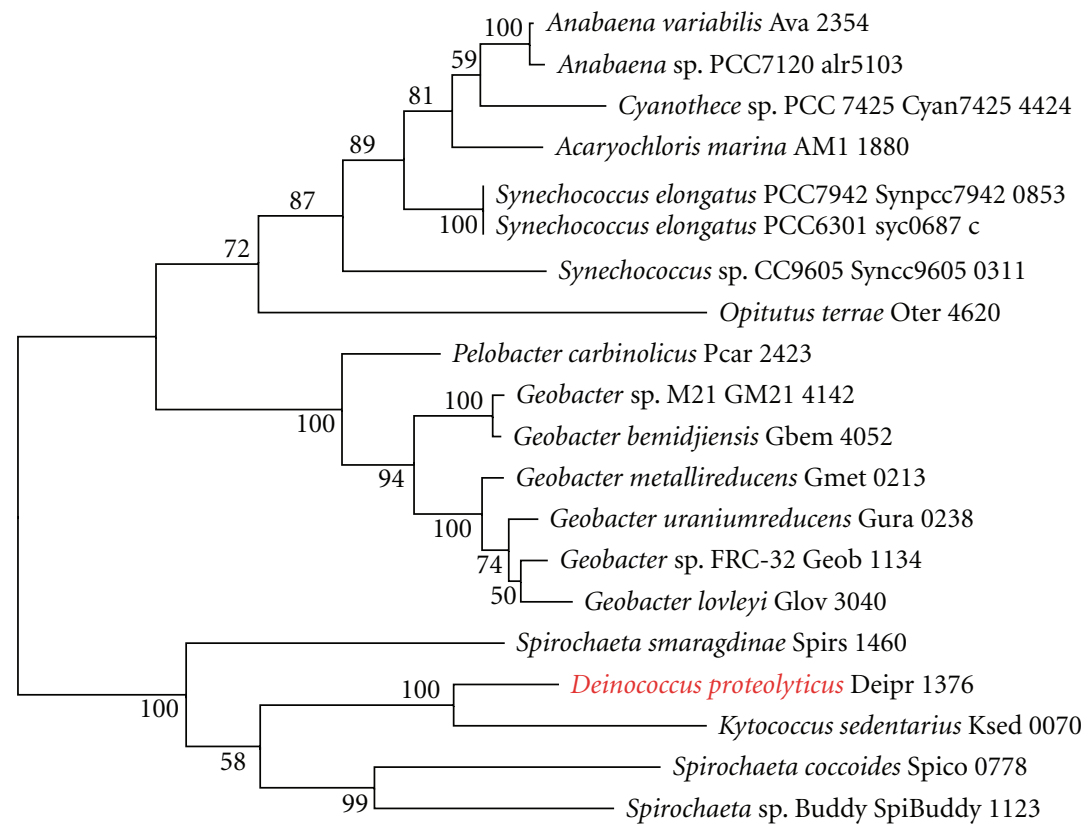

$\longmapsto 0.1$

Figure 2: Phylogenetic relationship between Deinococcus proteolyticus LL-diaminopimelate aminotransferase and related proteins. Multiple alignment was obtained using the top 20 amino acid sequences of the BLASTp search result for D. proteolyticus LL-diaminopimelate aminotransferase (Deipro 1376), as based on the KEGG database. The maximum-likelihood tree was constructed using MEGA software version 5 [12]. The WAG model was used as the amino acid substitution model. The nearest neighbor interchange was used for the maximum-likelihood heuristic method. The $\gamma$-distributed rate was considered, and the number of discrete $\gamma$ categories was 3 . Bootstrap analysis was performed with 100 replicates. Red indicates $D$. proteolyticus.

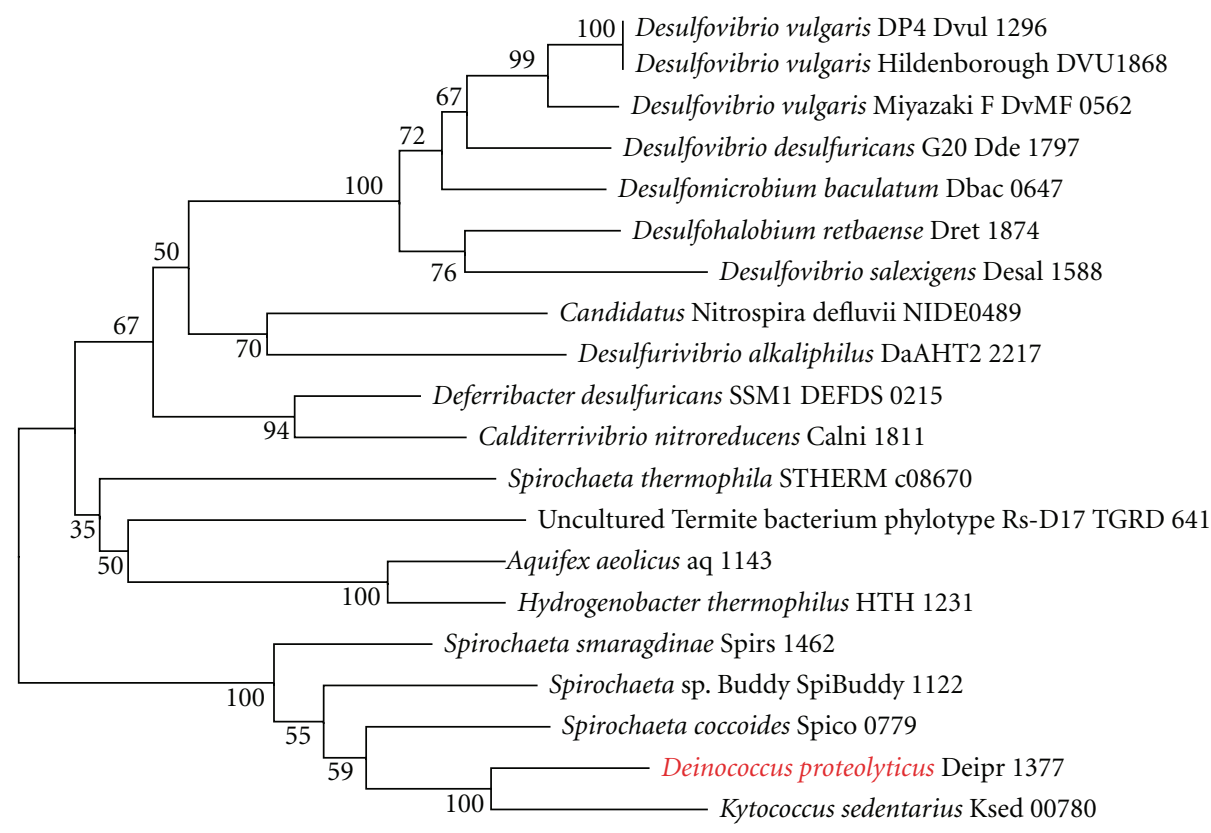

$\longmapsto 0.1$

Figure 3: Phylogenetic relationship between Deinococcus proteolyticus dihydrodipicolinate synthase and related proteins. Multiple alignment was obtained using the top 20 amino acid sequences of the BLASTp search result for D. proteolyticus dihydrodipicolinate synthase (Deipro 1377), as based on the KEGG database. The maximum-likelihood tree was constructed using MEGA software version 5 [12]. The WAG model was used as the amino acid substitution model. The nearest neighbor interchange was used for the maximum-likelihood heuristic method. The $\gamma$-distributed rate was considered, and the number of discrete $\gamma$ categories was 3. Bootstrap analysis was performed with 100 replicates. Red indicates $D$. proteolyticus. 


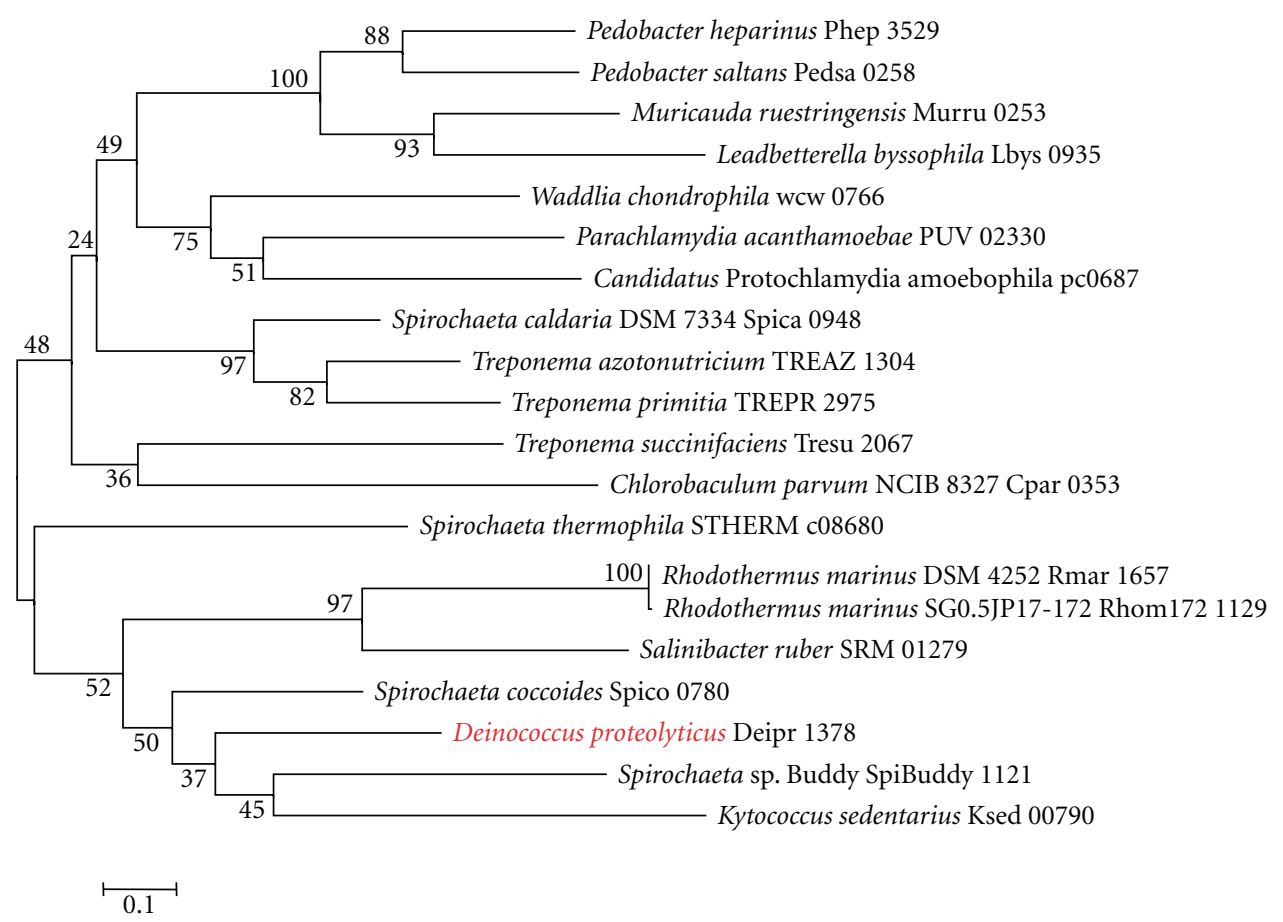

Figure 4: Phylogenetic relationship between Deinococcus proteolyticus dihydrodipicolinate reductase and related proteins. Multiple alignment was obtained using the top 20 amino acid sequences of the BLASTp search result for D. proteolyticus dihydrodipicolinate reductase (Deipro 1378), as based on the KEGG database. The maximum-likelihood tree was constructed using MEGA software version 5 [12]. The WAG model was used as the amino acid substitution model. The nearest neighbor interchange was used for the maximum-likelihood heuristic method. The $\gamma$-distributed rate was considered, and the number of discrete $\gamma$ categories was 3 . Bootstrap analysis was performed with 100 replicates. Red indicates D. proteolyticus.

hydrolase, LysW- $\gamma$-L- $\alpha$-aminoadipate kinase, LysW- $\gamma$-L- $\alpha$ aminoadipyl-6-phosphate reductase, $\alpha$-aminoadipate-LysW ligase LysX, LysU, LysT, and homocitrate synthase. In addition, we analyzed the distribution of each of the following 6 enzymes related to lysine biosynthesis through the DAP pathway: aspartate kinase, aspartate-semialdehyde dehydrogenase, dihydrodipicolinate synthase, dihydrodipicolinate reductase, LL-diaminopimelate aminotransferase, and diaminopimelate decarboxylase.

Homologous genes were selected on the basis of BLASTp search results by using each $T$. thermophilus enzyme for lysine biosynthesis through the AAA pathway and each $D$. proteolyticus enzyme for lysine biosynthesis through the DAP pathway. Multiple alignments were obtained using 20 amino acid sequences, with the highest to the 20th highest score by the BLASTp result. Maximum-likelihood trees were constructed using MEGA software version 5 [12]. The WAG model [13] was used as the amino acid substitution model. The nearest neighbor interchange was used for the maximum-likelihood heuristic method. The $\gamma$-distributed rate was considered, and the number of discrete $\gamma$ categories was 3 . Bootstrap analysis was performed with 100 replicates.

\section{Results and Discussion}

Genes homologous to the T. thermophilus genes for lysine biosynthesis through the AAA pathway were found to be widely distributed in bacteria belonging to the Deinococcus-Thermus phylum, except for $D$. proteolyticus (Table 1). Among the 13 organisms examined, Marinithermus, Oceanithermus, and Truepera have the largest gene cluster, containing 8 lysine biosynthetic genes (Table 1). In each phylogenetic analysis of the 10 enzymes, lysine biosynthetic genes of the Deinococcus-Thermus phylum were found to have a common ancestor (See in Supplementary Material Figures S1-S10 available online at doi:10.1155/2012/745931). We hypothesize that a common ancestor of the Deinococcus-Thermus phylum biosynthesized lysine through the AAA pathway.

In contrast, the distribution of genes for lysine biosynthesis through the DAP pathway was found to be limited in the Deinococcus-Thermus phylum (Table 2). Thus, LLdiaminopimelate aminotransferase and dihydrodipicolinate reductase were identified in no bacteria other than $D$. proteolyticus (Table 2). This observation supports our hypothesis that a common ancestor of the Deinococcus-Thermus phylum biosynthesized lysine not through the DAP pathway, but through the AAA pathway.

Interestingly, $D$. proteolyticus was found to have the genes for lysine biosynthesis through the DAP pathway (Table 2). D. proteolyticus has 2 diaminopimelate decarboxylases, namely, Deipro 0627 and Deipro 1375 (Table 2), which are structurally different from each other. Because Deipro 1375 forms a gene cluster with other genes for lysine 
biosynthesis through the DAP pathway, we used Deipro 1375 as a query sequence in the BLASTp search. Each phylogenetic tree based on diaminopimelate decarboxylase (Figure 1), LL-diaminopimelate aminotransferase (Figure 2), dihydrodipicolinate synthase (Figure 3), and dihydrodipicolinate reductase (Figure 4) showed that the D. proteolyticus enzyme is closely related to that of the genera Kytococcus (a member of Actinobacteria) and Spirochaeta (a member of Spirochaetes) (Figures 1-4). The 3 phyla Actinobacteria, Deinococcus-Thermus, and Spirochaetes do not form a monophyletic lineage in the phylogenetic tree, as based on genomewide comparative studies [14]. In addition, the 4 genes encoding diaminopimelate decarboxylase, LLdiaminopimelate aminotransferase, dihydrodipicolinate synthase, and dihydrodipicolinate reductase are clustered in each genus (Figures 1-4). Thus, these findings strongly suggested that a DNA fragment including the $4 \mathrm{D}$. proteolyticus genes was horizontally transferred from a phylogenetically distant organism. This horizontal transfer event may have induced the loss of the genes for lysine biosynthesis through the AAA pathway in D. proteolyticus.

\section{References}

[1] W. G. Weisburg, S. J. Giovannoni, and C. R. Woese, "The Deinococcus-Thermus phylum and the effect of rRNA composition on phylogenetic tree construction," Systematic and Applied Microbiology, vol. 11, pp. 128-134, 1989.

[2] E. Griffiths and R. S. Gupta, "Distinctive protein signatures provide molecular markers and evidence for the monophyletic nature of the Deinococcus-Thermus phylum," Journal of Bacteriology, vol. 186, no. 10, pp. 3097-3107, 2004.

[3] M. Kanehisa, S. Goto, Y. Sato, M. Furumichi, and M. Tanabe, "KEGG for integration and interpretation of largescale molecular datasets," Nucleic Acids Research, vol. 40, pp. D109-D114, 2012.

[4] H. Nishida, R. Abe, T. Nagayama, and K. Yano, "Genome signature difference between Deinococcus radiodurans and Thermus thermopilus," International Journal of Evolutionary Biology, vol. 2012, Article ID 205274, 6 pages, 2012.

[5] A. M. Velasco, J. I. Leguina, and A. Lazcano, "Molecular evolution of the lysine biosynthetic pathways," Journal of Molecular Evolution, vol. 55, no. 4, pp. 445-459, 2002.

[6] H. Nishida, M. Nishiyama, N. Kobashi, T. Kosuge, T. Hoshino, and H. Yamane, "A prokaryotic gene cluster involved in synthesis of lysine through the amino adipate pathway: a key to the evolution of amino acid biosynthesis," Genome Research, vol. 9, no. 12, pp. 1175-1183, 1999.

[7] T. Kosuge and T. Hoshino, "Lysine is synthesized through the $\alpha$-aminoadipate pathway in Thermus thermophilus," FEMS Microbiology Letters, vol. 169, no. 2, pp. 361-367, 1998.

[8] N. Kobashi, M. Nishiyama, and M. Tanokura, "Aspartate kinase-independent lysine synthesis in an extremely thermophilic bacterium, Thermus thermophilus: lysine is synthesized via $\alpha$-aminoadipic acid not via diaminopimelic acid," Journal of Bacteriology, vol. 181, no. 6, pp. 1713-1718, 1999.

[9] H. Nishida, "Distribution of genes for lysine biosynthesis through the aminoadipate pathway among prokaryotic genomes," Bioinformatics, vol. 17, no. 2, pp. 189-191, 2001.

[10] H. Nishida and I. Narumi, "Phylogenetic and disruption analyses of aspartate kinase of Deinococcus radiodurans,"
Bioscience, Biotechnology and Biochemistry, vol. 71, no. 4, pp. 1015-1020, 2007.

[11] M. V. Omelchenko, Y. I. Wolf, E. K. Gaidamakova et al., "Comparative genomics of Thermus thermophilus and Deinococcus radiodurans: divergent routes of adaptation to thermophily and radiation resistance," BMC Evolutionary Biology, vol. 5, article 57, 2005.

[12] K. Tamura, D. Peterson, N. Peterson, G. Stecher, M. Nei, and S. Kumar, "MEGA5: molecular evolutionary genetics analysis using maximum likelihood, evolutionary distance, and maximum parsimony methods," Molecular Biology and Evolution, vol. 28, no. 10, pp. 2731-2739, 2011.

[13] S. Whelan and N. Goldman, "A general empirical model of protein evolution derived from multiple protein families using a maximum-likelihood approach," Molecular Biology and Evolution, vol. 18, no. 5, pp. 691-699, 2001.

[14] H. Nishida, T. Beppu, and K. Ueda, "Whole-genome comparison clarifies close phylogenetic relationships between the phyla Dictyoglomi and Thermotogae," Genomics, vol. 98, no. 5, pp. 370-375, 2011. 

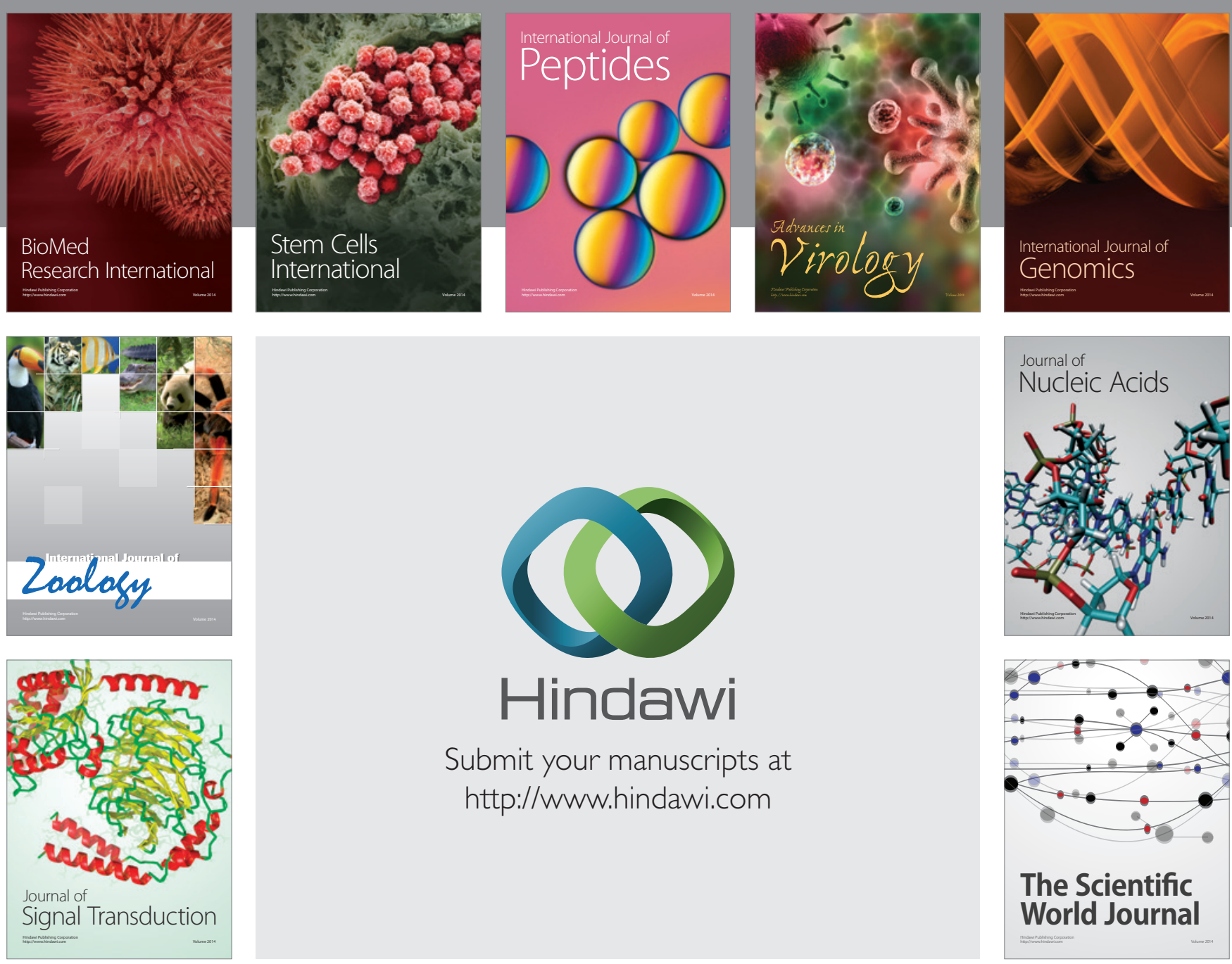

Submit your manuscripts at

http://www.hindawi.com
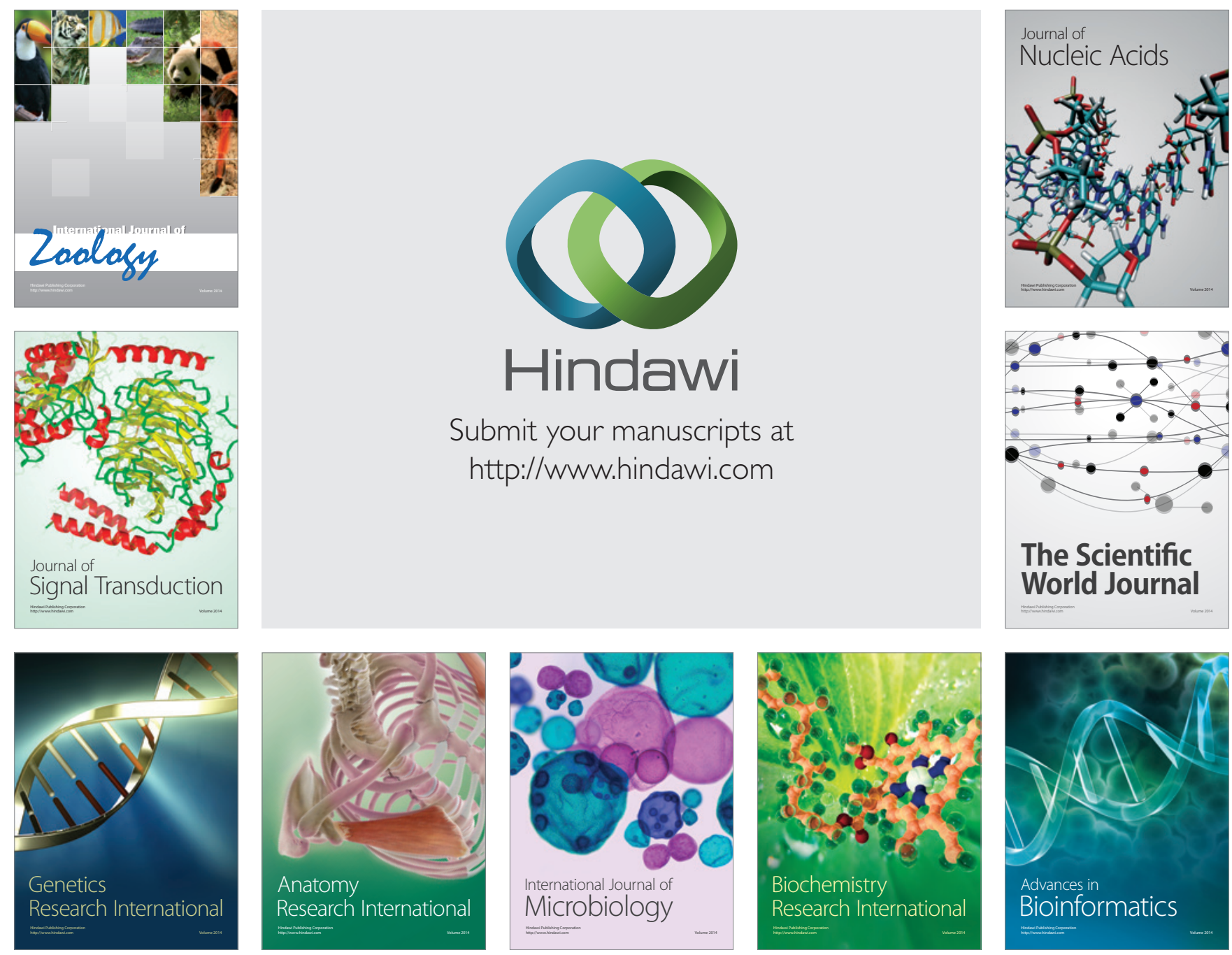

The Scientific World Journal
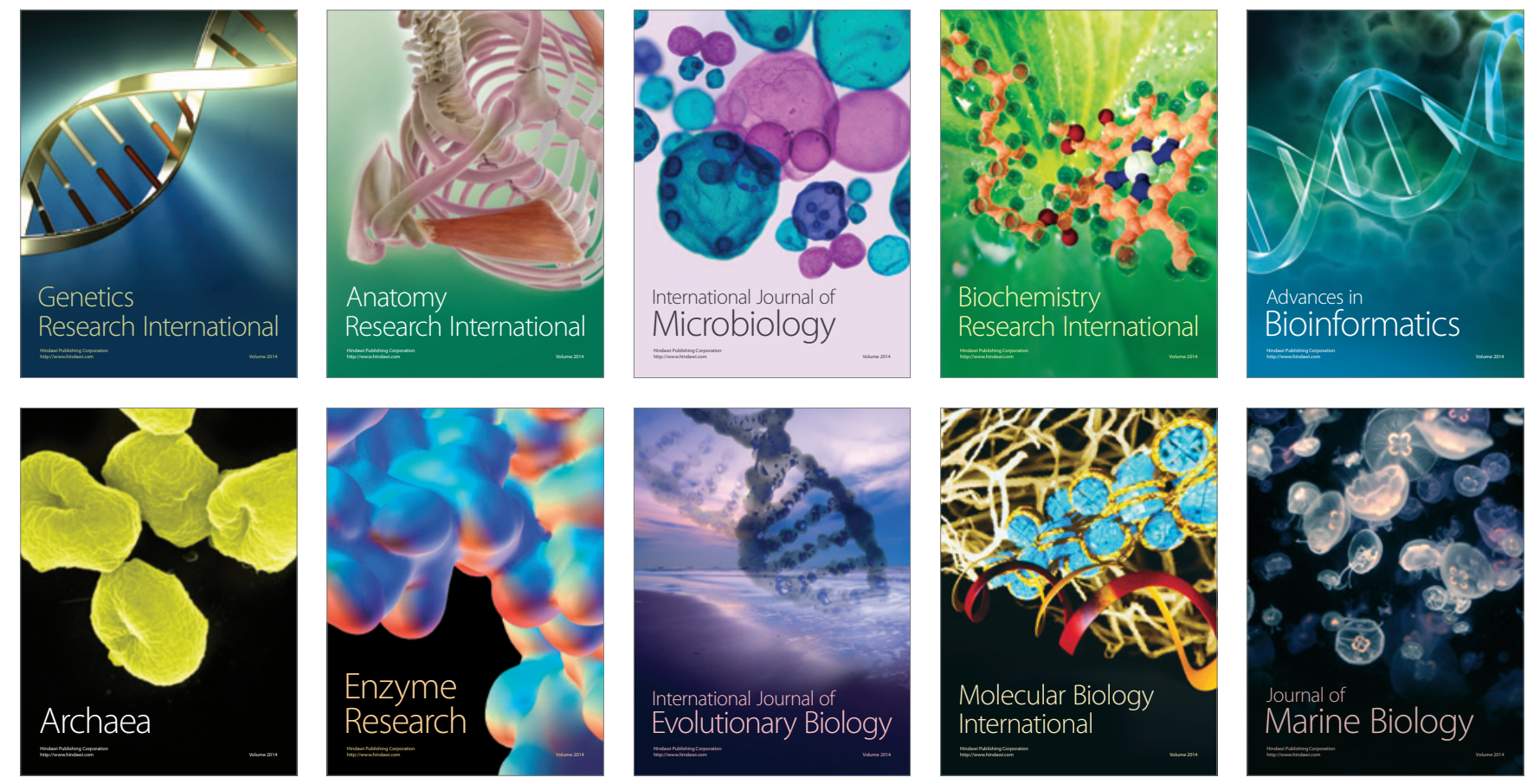